\title{
The Effects of Enhancing Prospective EFL Teachers' Knowledge Management Strategies in Virtual Learning Environments on Their Ideational Flexibility and Engagement
}

\author{
Ammar Abdullah Mahmoud Ismail \\ Sohag Faculty of Education, Sohag University, Egypt \\ E-mail: abdallai2000@yahoo.com
}

Received: 03-10-2016

Published: 01-03-2017
Accepted: 07-12-2016

doi:10.7575/aiac.ijalel.v.6n.2p.154
Advance Access Published: January 2017

URL: http://dx.doi.org/10.7575/aiac.ijalel.v.6n.2p.154

\begin{abstract}
The last few years have witnessed an increased interest in moving away from traditional language instruction settings towards more hybrid and virtual learning environments. Face-to-face interaction, guided practice, and uniformity of knowledge sources and skills are all replaced by settings where multiplicity of views from different learning communities, interconnectedness, self-directedness, and self-management of knowledge and learning are increasingly emphasized. This shift from walled-classroom instruction with its limited scope and resources to hybrid and virtual learning environments with their limitless provisions requires that learners be equipped with requisite skills and strategies to manage knowledge and handle language learning in ways commensurate with the nature and limitless possibilities of these new environments. The current study aimed at enhancing knowledge management strategies of EFL teachers in virtual learning environments and examine the impact on their ideational flexibility and engagement in language learning settings. A knowledge management model was proposed and field-test on a cohort of prospective EFL teachers in the Emirati context. Participants were prospective EFL teachers enrolled in the Methods of Teaching Courses and doing their practicum in the Emirati EFL context. Participants' ideational flexibility was tapped via a bimethodical approach including a contextualized task and a decontextualized one. Their engagement in virtual language learning settings was tapped via an engagement scale. Results of the study indicated that enhancing prospective EFL teachers' knowledge management strategies in virtual learning environments had a significant impact on their ideational flexibility and engagement in foreign language learning settings. Details of the instructional intervention, instruments for tapping students' ideational flexibility and engagement, and results of the study are discussed. Implications for foreign language teaching/learning along with suggestions for further research are also provided.
\end{abstract}

Keywords: Knowledge management, ideational flexibility, student engagement

\section{Introduction}

The last few years have witnessed a revived interest in creativity and productivity in different learning environments fuelled by a paradigm shift towards knowledge-driven development and knowledge-oriented educational practices. Knowledge has become a buzz word in different fields. Terms such as knowledge age, knowledge society, knowledgedriven businesses, knowledge economy, and knowledge-based development are increasingly invading different fields, both academic and work-related. Producing and advancing knowledge are seen as essential keys to success and advancement in these fields.

In this emerging knowledge age, creativity has become one of the core competencies, along with collaboration, communication, and critical thinking (Barbot et al., 2015; Kaufman \& Beghetto, 2009). It is increasingly recognized as a valuable asset for individuals in their daily problem solving and their professional careers (Besancon et al., 2013). This is particularly important in language teaching that is heavily dependent on both creativity and knowledge. The teaching profession depends heavily on teachers' capabilities to provide creative solutions for instructional problems and issues. Improvisation, advancement of teaching theories and applications thereof, and the creative adaptation of universal pedagogical knowledge all need creative minds.

This paradigm shift towards knowledge-driven practices in different realms of life followed a corresponding shift in educational settings from knowledge transmission to knowledge construction pedagogies. In the former context, as Kumaravadivelu (2012) argues, the role of a teacher educator was passing bits of professional knowledge to teacher candidates. The implicit assumption, according to Freeman and Johnson (1998, cited in Moradkhani et al., 2013), was that in order to enhance student achievement, teachers needed to learn a set of tried-and-tested behaviors with predictable learning outcomes. The latter context, informed by social constructivism which regards knowledge as the product of human activity, the importance of managing and advancing pedagogical knowledge and developing creativity within language learning settings is recognized (Chen et al , 2009). 
Accordingly, as Kumaravadivelu (2012) argues, teacher educators' mission statement changed from providing a set of ready-made techniques to shaping teacher candidates' thinking and creative potentials. With this new description of duties, teachers have become essential agents for change in the teaching profession (Margolin, 2011). New learning environments target not only developing students' ability to utilize diverse information sources but also their ability to synthesize coherent knowledge from fragmentary information (Johnson, 2009). As stated by Bereiter and Scardmialia (2010), "the emerging knowledge age poses an educational challenge that can be best met by adopting knowledge management and knowledge building pedagogies" (P. 11).

Yet, this shift towards creativity, constructivist approaches and knowledge building pedagogies has not heretofore had it full potential. Two aspects of the learning environment, Davies et al's (2013) argue, are most influential in inducing creativity and productivity therein. These are the structure, operation, and atmosphere of the classroom and the attitude of the teacher towards creativity. It seems that the existing learning environments are inadequate to provide for these aspects. According to Kudryavtseu (2011), limitation of resources, pressure to conform, competition and rote learning compromise the development of creativity. Students graduating from higher education institutions, as Bedord (2013) states, "need to be more than 'book ready' and 'theory rich'; they need to be 'work ready' and able to do knowledge management' "(P.199). As Mourgues et al (2014) state, inculcating a culture of openness and innovation is a prerequisite for creativity and knowledge building to flourish and pay off. Applied to language teaching settings, prospective teachers need more than mere mastery of the theoretical underpinnings of existing pedagogical knowledge. They need as well to learn how to manage existing knowledge and advance it for more adaptability to their context of language instruction.

Empirical research in different educational contexts world-wide carries evidence that current learning environments are inadequate for furthering knowledge building and creativity in educational institutions. The conclusion, as summarized by Bennett and Bennett (2008), is that the focus on surface and shallow knowledge is still prevailing at the expense of deep knowledge. In line with this conclusion, the National Research Council has expressed a concern that the US education system teaches students using a mile wide and inch deep approach (National Research Council, 2000). Chickering and his colleagues (2005) argued that "in Scotland, Canada and, Australia 90 percent of student learning was surface learning"(P.133). This, as Sousa (2006) argues, will lead to inability of future adults to address problems that require deep learning and creative solutions.

In the Arab context of higher education the situation is even worse. The Arab Knowledge Report 2014 explicitly stated that "higher education institutions in the Arab world are not coping with the requirements of knowledge society" (P. 97), that "there is a gap between the knowledge provided to students and the labor market requirements" (P.148), and that "Arab States are still far from what is required to achieve tangible results in building the knowledge society" (P. 17). Similarly, the Arab Human Development Reports 2002 and 2003 (cited in the Arab Knowledge Report-2014) confirmed the existence of a deficiency in the process of building generations to acquire knowledge and a decline in many areas of knowledge production. Likewise, the Knowledge Index prepared by the World Bank (cited in the Arab Knowledge Report-2014) indicates a mediocre Arab performance and an increasing gap between the Arab region and the other regions of the world (P.254). The common conclusion in these reports is that education in the Arab states does not adequately prepare generations to gain the experience of knowledge and skills which support creativity and productivity.

The context of foreign language education is no exception to these conclusions. In a number of studies on EFL teachers in different contexts it was concluded that transmissive instructional practices in terms of surface-level teaching and learning orientations are still prevailing (Ali \& Ammar, 2005; Ammar \& Abdel-Majeed, 2006). As well, studies indicated that EFL students are likely to adopt maladaptive stances towards knowledge, how it is acquired and evaluated, and how knowing occurs (Ali \& Ammar, 2005). Conclusions of these studies are in line with conclusions on foreign language education in other settings. As Dinkleman et al (2006) and Murray and Male (2005) argue, the type of knowledge teacher-educators need to have and the way they acquire that knowledge have been largely ignored. Consequently, a call for enhancing educators' pedagogical knowledge and instructional practices thereof for more orientation towards productivity, creativity, and knowledge advancement has been voiced by many researchers and educators (Jang et al, 2013; Van-Driel \& Berry, 2012; Mohamed et al, 2008; Major \& Balmer, 2006; Warner, 2006)

The emergence of virtual learning environments and connectivist approaches to education (Siemens, 2008) added more momentum. The era of learning environments of buildings and books has increasingly been replaced by an era of virtual and learning management platforms. The new learning environments have potential chances for advancing knowledge creation, creativity, and productivity in educational settings. Evidence provided so far indicates that online, hybrid, virtual, personal, or internet-mediated learning environments with their many learning applications are more likely to enhance foreign language performance (Akbari et al, 2016). They are especially useful and conducive to the improvement and promotion of language skills (Brick, 2011a; Lomicka \& Lord, 2009), increasing students' participation in various learning activities (Brick, 2011b; Mills, 2009), and influencing students' motivation in a positive way (Dunne et al. 2012; Chen et al., 2010).

Yet, two main problems are still haunting these learning environments and thus need to be tackled in language research especially in foreign language contexts. These are the inadequacy in knowledge building and management, on the one hand, and the disengagement in virtual language learning activities, on the other. The former relates to the surface and shallow instructional practices prevailing therein at the expense of deeper learning. According to Bennett and Bennett (2008), existing practices focus in most part on surface and shallow knowledge at the expense of deep knowledge. 
Bereiter and Scardamalia (2010) see that most of what takes place in educational settings falls under the knowledge telling or knowledge transforming approaches, both providing little chance for creative knowledge building and advancement. As Bereiter and Scardamalia (2010) state, existing environments "mitigate against inquiry, independent learning, and thinking" (P.5). According to Touchan (2010), there is a profound focus on surface learning represented in memorization of facts and concepts without reflection, and a profound orientation towards assessment-related practices.

The latter problem relates to poor student engagement in virtual learning activities. Engagement here refers to students' behavioral, emotional, and cognitive involvement in learning activities (Fridricks, Blumenfeld \& Pans, 2004: 62-63). This engagement is seen by many educators as a good predictor of quality educational outcomes (Kahu, 2013; Shreiner \& Louis, 2011; Garrett, 2011; Pascarella et al. 2010; Chen et al., 2010). As well, it has also been considered a good predictor of quality assurance in higher education (Coates, 2006), and a key factor in connectivist learning (Kop, 2011). When students are not adequately engaged, as Kahn (2014) and Akbari et al. (2016) argue, they feel that they are outsiders in respect of their capacity to participate in the unfolding discourse, which in turn affects negatively their academic performance and persistence.

It seems that both problems are experienced in the foreign language context of the current study, based on the observations of the researcher while teaching the TEFL courses of the English study program. According to the syllabus descriptions of the TEFL courses, students in the English program are expected to " show critical awareness of the principles underlying approaches to foreign language instruction and an ability to creatively adapt them to the Emirati context of foreign language education" (ADU Quality Assurance Manual). As part of the TEFL courses requirements, students are asked to write critical reports on instructional issues studied in assigned course readings. Based on the observations of the researcher of the current study, most students' reports were a mere cut-and-paste practice with very little originality, or critical processing of considered pedagogical knowledge. What they wrote did not go much beyond content studied in assigned textbooks. Ability to creatively adapt studied content or think of alternatives to improve their instructional practices in their practicum experience was very limited. Perkel (2008) called such practices "the copy-and-paste literacy" (P.204)

\subsection{Statement of the Problem}

It is clear from the above introduction that prospective EFL teachers of ADU University suffer from shallow learning performance and disengagement in foreign language settings in general and in virtual learning environments in particular. Consistent with the emerging connectivist pedagogies (Siemens, 2008), Abu Dhabi University adopted Blackboard as its educational platform where a great amount of instruction occurs online. Instructors are constantly encouraged to migrate from traditional classroom teaching practices towards more blended, virtual, or online learning environments. Examination of students' online learning practices and the quality of the projects they submitted as part of their TEFL course requirements showed incompetence in handling tasks and shallow learning performance in virtual environments.

Based on the researcher's observations and the documented need in pertinent literature to move towards deeper knowledge and higher levels of student engagement, the current study was an attempt at enhancing the knowledge management strategies of prospective EFL teachers and studying its impact on their creativity and engagement in foreign language instructional settings. Creativity here is measured in terms of their ideational flexibility, i.e. their ability to produce a rich pool of different alternatives to handle language teaching/learning issues. Engagement is measured in terms of their persistence and participation in virtual language learning settings.

Thus, the study provided answers to these two research questions.

1. What is the effect of enhancing prospective EFL teachers' knowledge management strategies in virtual learning environments on their ideational flexibility in foreign language instructional settings?

2. What is the effect of enhancing prospective EFL teachers' knowledge management strategies in virtual learning environments on their engagement in foreign language instructional settings?

\subsection{Significance of the Study}

The significance of the current study stems from a set of considerations. First, the study deals with knowledge management $(\mathrm{KM})$, an emerging paradigm that is relatively new in educational settings (Becerra-Fernandez \& Gudi, 2008). According to Bereiter and Scardamalia (2014, 2010), knowledge building and knowledge management pedagogy is more likely to be the future alternative to the existing pedagogical approaches. Yet, as Singh (2012) argues, "despite the rapid proliferation of KM practice in other fields such as Computer-Assisted Systems Engineering (CASE), Business Process Engineering (BPE), Enterprise Resource Planning (ERP), and other IT inventions, unfortunately, the formal teaching process at colleges and universities generally lag many years behind the active usage and leveraging of these practices" (P. 194). The very few studies conducted in educational settings were descriptive in nature and did not handle knowledge management in its entirety. Language learning settings in general and foreign language contexts in particular did not receive due attention.

Second, the study is concerned with pedagogical knowledge, a field that has not received due attention in research literature on knowledge management or epistemology. According to Evens et al (2015) pedagogical content knowledge refers to the teacher's deep understanding of the processes and practices or method of teaching and learning. In this sense, it is different from academic content knowledge that refers to knowledge of the disciplinary or subject-specific content that students study in different academic majors. According to Moradkhani et al. (2013), knowing a particular 
subject matter is one thing and having the knowledge to make it teachable quite another. This pedagogical knowledge, as Moradkhani et al. (2013), and Evens et al. (2015) argue, is of particular significance as its advancement is a prerequisite to the advancement of academic content knowledge.

Third, the current study focuses on knowledge building pedagogy as an approach to advancing the pedagogical knowledge of prospective EFL teachers. Most existing research literature and instructional interventions thereof, as Bereiter and Scardamalia (2014) argue, focus on the transfer and exploitation of established pedagogical knowledge. Exploratory creation of new knowledge has not received due attention. Scardmialia and her colleagues (Bereiter \& Scardamalia, 2014; Scardamalia et al, 2012; Scardamalia \& Bereiter, 2007; Scardamalia \& Bereiter, 2006) see knowledge building pedagogy the future alternative to the existing approaches of instruction.

Fourth, the study focuses on knowledge management in virtual learning environments. These environment avail numerous advantages for students, including greater flexibility, abundance of knowledge sources, and control over the time they have to think, reflect and respond (Swan, 2004). Yet, despite these advantages, it seems that when students long educated in traditional learning environments migrate to connectivist, virtual, or blended learning environments they show dysfunction in learning and academic achievement. Learning mechanisms and practices in the new environments are very different from those deemed adequate in the traditional environments. Teachers are no longer there to provide help and close guidance the way used to in traditional learning environments. Migration towards connectivist learning environments, as Miyazoe and Anderson (2010) argue, requires that students be equipped with prerequisite strategies to manage the abundance of knowledge made available in these new environments, an issue that has not been heretofore duly addressed in language research and educational settings.

Finally, the study focuses on students' cognitive engagement in virtual learning environments, an issue that has been raised in pertinent research literature. As Kahn (2014) and Zaqout and Abbas (2012) stated, student disengagement in virtual learning environments is a major concern for educators and researchers. Students' self-initiation and persistence whilst working independently of teachers in VLEs are determinant factors in the success or failure of their academic endeavors therein (Levy \& Campbell, 2007; Zhao \& Kuh, 2004; Pawan et al, 2003). Engaged students can dig deeper for creative ideas and become more subsumed in academic work. Whereas social and emotional engagement in virtual learning environment have received attention, cognitive engagement, as Baron and Corbin (2012) and Moore et al. (2008) argue, has not been duly addressed.

\subsection{Definition of terms}

The following definitions of terms have been adopted in the current study:

Engagement: Engagement refers to "the amount of effort and type of processing strategies that students use for learning" (Ravindran et al., 2005: 222).

Ideational Flexibility: Ideational flexibility is "the tendency to generate a heterogeneous pool of responses, or to use a variety of categories and themes when producing ideas" (Runco, 2001: 347).

Knowledge management: Knowledge Management (KM) refers to the "processes of knowledge acquisition, creation, refinement, storage, transfer, sharing, and utilization" (King, 2009: 3)

\section{Review of Literature}

Research on knowledge management has gained momentum in the last few years due to the competitive advantage of knowledge in different fields (Zhao, 2010; Chu et al., 2009; Wang \& Jia, 2005). The relatively recent emergence of knowledge management as a paradigm in educational settings has been fuelled by two main developments. The first is the shift in learning environments from walled classrooms to connectivist workspaces and learning management systems (Siemens, 2008). This shift has brought about dramatic changes in the nature of knowledge in terms of dynamicity, integration, multiplicity of knowledge sources, and diversity in perspectives and stances, which in turn necessitates that learners be equipped with requisite skills and strategies to manage knowledge for better functioning in these knowledge-rich environments.

The second is the shift from individualistic and competitive classrooms to collaborative learning communities. Educators and researchers (Chatti et al, 2010; So \& Brush, 2008; Liu et al, 2007; Shea, 2006; Palloff \& Pratt, 2005) came to the conclusion that true learning occurs in a community through collaboration and interaction amongst community members. This is not restricted to members of the learning community (COL), but extends to collaboration and interaction with members of other communities, including the community of interest (COI), and the community of practice (COP). This collaborative practice, as Scardamalia and Bereiter (2007) and Zhao and Kuh (2004) argue, is more likely to induce higher levels of engagement and better academic performance.

Initial research on knowledge management in educational settings carried evidence that adopting knowledge management pedagogies has brought about better gains in student performance and academic achievement. For example, Mamta \& Jayanthi (2012) found out that adopting knowledge management approaches has led to quality teaching and learning processes. As well, knowledge management brought about better story writing performance by primary students (Chen et al. (2009). Students took the initiative to generate ideas, care about each other, and reflect on their own and peers' ideas. Likewise, Scardamalia and Bereiter (2009) concluded that adopting knowledge building pedagogy induced advances in literacy, core content knowledge, and the ability to learn from text. Similar conclusions were expressed by researchers and educators in different settings (Keong \& Subhi, 2015; Hiew \& Hoon, 2014; Usman \& Oyefolahan, 2014; Zaqout \& Abbas, 2012). 
Yet, despite this significant impact of knowledge management on student performance and academic achievement, the formal teaching process at colleges and universities, as Singh (2012) argues, "generally lag many years behind the active usage and leveraging of these practices in the real world" (P.194). In language learning contexts, as Chen et al (2009) argue, little research has examined language learning from a knowledge building or knowledge management perspective. The few studies that have been conducted so far have been descriptive in nature. Instructional interventions to promote knowledge management in language settings are very scant. Moreover, as Konig et al (2016) state, despite an increasing research interest in subject-specific knowledge, the scientific understanding regarding teachers' professional knowledge for teaching English as a foreign language (TEFL) is very limited. Similar conclusions regarding the paucity of research on pedagogical knowledge of language teachers and the scarcity of instructional interventions to enhance these strategies have been made by many researchers and language educators (Evens et al., 2015; O’Dell \& Hubert, 2011; Ge et al., 2006; Wright, 2005; Ruth et al., 2003).

\subsection{Existing Models of Knowledge Management}

Despite the inexistence of well-developed models of knowledge management in the literature that provide instructional frameworks applicable in learning contexts, three theoretical conceptualizations can be drawn on for building a knowledge management model. The first of these is Belenky and colleagues' Ways of Knowing Model (1998) that describes the stages of an individual's epistemic development and the ways of knowing deployable in each stage. Epistemic development here refers to the development of beliefs regarding the nature of knowledge and the process of knowing (Hofer, 2008; Schommer-Aikins \& Easter, 2009). The model covers five basic stages of development, each with a predominant way of knowing individuals are most likely to deploy when handling knowledge situations. These include silence, received knowledge, subjective knowledge, procedural knowledge, and constructed knowledge.

According to Belenky and colleagues (1998), individuals in the silence stage have ways of knowing that are limited to the present, the actual, the concrete, and the specific. Obeying authorities is of utmost importance for keeping out of troubles, and speaking of self is almost impossible. In the received knowledge stage, individuals have little confidence in their own voices and are apt to think of authorities as sources of knowledge because of their statues. They believe in the wrong/right answers to questions. In the subjective knowledge stage, a sense of voice arises and individuals develop beliefs that truth comes from within the person. First -hand experience is a valuable source of knowledge. The predominant learning mode in this stage is inward listening and watching.

Procedural Knowledge marks a shift in individuals' views regarding knowledge according to Belenky and colleagues' model (1998). Here, individuals develop views that knowing requires careful observation and analysis. Knowledge is a process of looking at things and handling problematic issues. Two ways of knowing are essential in this stage: connected and separate knowing. These ways of knowing determine to a great extent students' approaches in language learning settings. Learners with a strong belief in connected knowing initially take an emphatic stance and attempt to sympathize with the knowledge source, identify with the source's perspective, and understand the point being made. Only after understanding the point do they become ready to be more critical. In contrast, learners with a stronger belief in separate knowing take an oppositional stance first. Functioning as a devil's advocate, they question, doubt, and wait for evidence before they attempt to deeply understand the information or empathize with the knowledge source (Khine \& Hayes, 2010; Khine, 2008))

Constructed Knowledge constitutes the peak of individual's epistemic development. Here, knowledge is conceived of as integrated and constructed rather than received from knowledgeable authorities. Reality cannot be compartmentalized. Individuals start to develop a narrative sense of self and show high tolerance for internal contradiction and ambiguity. As Belenky et al's (1998) argue, when knowers develop a conviction that knowledge is relative and that they can construct and reconstruct frames of reference, they feel responsible for examining, questioning, and developing the systems that they will use for constructing knowledge.

What is significant about this model is that it provides a precise description of the epistemic development of individuals and the epistemic beliefs they are likely to develop in each stage of their epistemic development. These epistemic stances are likely to impact their knowledge management strategies and mechanisms and thus would determine the success or failure of their knowledge management endeavors in educational settings. Yet, the Ways-of- knowing model does not translate into an instructional design that can be used in classrooms. It does not have a procedural framework that teachers can follow to enhance the knowledge management performance of their students.

The second model of knowledge management proposed in the literature is the Knowledge Chain Model (Singh, 2012) developed in business contexts. It identifies and characterizes knowledge management activities an organization can focus on to achieve competitiveness. It is comprised of five primary activities that an organization's knowledge processors perform in manipulating knowledge resources, plus four secondary activities that support and guide their performances. The primary activities include knowledge acquisition, selection, generation, assimilation, and emission. Knowledge Acquisition refers to the process of acquiring knowledge from external sources and making it suitable for subsequent use. Knowledge selection focuses on filtering acquired knowledge based on value and applicability. Knowledge generation is concerned with producing knowledge by either discovery or derivation from existing knowledge. Knowledge assimilation refers to altering the state of an organization's knowledge resources by distributing and storing acquired, selected, or generated knowledge. Knowledge emission refers to embedding knowledge into organizational outputs for release into the environment. 
The secondary activities in the Knowledge Chain Model include knowledge leadership, knowledge coordination, knowledge control, and knowledge assessment (Singh, 2012). Knowledge leadership is concerned with establishing conditions that enable and facilitate fruitful conduct of knowledge management. Knowledge coordination refers to managing dependencies among knowledge management activities to ensure that proper processes and resources are brought to bear adequately at appropriate times. Knowledge control is concerned with ensuring that needed knowledge processors and resources are available in sufficient quality and quality. Knowledge assessment focuses on deciding on values of knowledge resources, knowledge processors, and their deployment (PP.199-200).

Two important contributions can be identified in this model. The first is that the model defines the knowledge processes that organizations need to perform to achieve their goals, including acquisition, selection, generation, assimilation, and emission. Second, the model defines secondary processes that would help facilitate the management of knowledge processes in the former activities. These include knowledge leadership, knowledge coordination, knowledge control, and knowledge assessment. Yet, as the model is created within business settings, it's more applicable in business organizations rather than educational contexts. It does not translate into an instructional framework that can be used in actual classroom settings as these are very different from the business settings and contexts.

The third model of knowledge management is Bereiter and Scardmailia's Knowledge Building (Bereiter \& Scardamalia, 2014; Scardamalia et al, 2012; Scardamalia \& Bereiter, 2007; Scardamalia \& Bereiter, 2006; Scardamalia \& Bereiter, 2002). Scardamalia and Bereiter (2002) define knowledge building as "the production and continual improvement of idea of value to a community through means that increase the likelihood that what the community accomplishes will be greater than the sum of individual contributions" (P.1371). As Scardmilia and Bereiter argue, knowledge building requires establishing effective knowledge building communities in terms of socio-cognitive norms. These norms include contributing to collective knowledge advances, constructive and considerate criticism, and mutual seeking of idea improvement.

The knowledge building approach of Bereiter and Scardamalia (2014) is a further development of two previous approaches; namely, knowledge telling and knowledge transforming. Both were developed in the context of composition writing. The former focuses on transmitting established knowledge and expertise through generations. Teachers transmit this knowledge to their students who are asked to acquire it and then pass it to their future students; the cycle goes on. The latter refers to transforming this knowledge through some cognitive processing to make it more adaptable to contexts of its consideration, which in turn requires deep learning and higher thinking abilities. Although the knowledge transforming approach seems a bit advanced compared to the knowledge telling one in terms of knowledge adaptability and the kind of cognitive processing required therein, still both focus on established knowledge with little opportunity to advance this body of knowledge or create new knowledge. According to Bereiter and Scardamalia (2010), most of what takes place in language classes falls under the knowledge telling or knowledge transforming approaches.

Twelve principles constitute the core of the knowledge building model (Bereiter \& Scardmailia, 2014, 2010). The first four pertain to the nature of ideas, the second four pertain to the community within which knowledge building is to take place, and the last four pertain to knowledge epistemology. The first set of principles are (1) real ideas authentic problems, (2) improvable ideas, (3) diversified ideas, and (4) pervasive knowledge building. According to Bereiter and Scardmailia $(2014,2010)$, ideas produced or appropriated are real ideas in the sense that they cause things to happen, create reactions and counter-reactions, and are created to handle authentic problems. They are improvable and can be further advanced. Although some ideas may turn out to be unimprovable, this is not to be judged in advance of effort to improve their quality, coherence, and utility. Idea diversity is essential to the development of knowledge advancement as it creates a rich environment for ideas to evolve into new and more refined forms. Knowledge building is pervasive in the sense that creative work with ideas is integral to all knowledge work. All tasks and activities represent an occasion for knowledge work.

The second set of principles relate to the knowledge building community. These include (1) community knowledge, (2) democratizing knowledge, (3) symmetric knowledge building, and (4) knowledge building discourse. According to Bereiter and Scardamalia $(2010,2002)$, knowledge building aims to produce knowledge of value to others. All participants are legitimate contributors to the shared goals of the community and all take pride in knowledge advances achieved by the group. Knowledge does not move only from the more knowledgeable to the less knowledgeable group; the ideal arrangement is one in which both groups gain in knowledge through their participation in a joint effort.

The last set of principles relate to epistemologies about knowledge, including (1) epistemic agency, (2) rise above, (3) authoritative uses of knowledge sources, and (4) concurrent transformative assessment. According to Bereiter and Scardamalia (2010), epistemic agency refers to the idea that participants recognize both a personal and a collective responsibility for success of knowledge building efforts. "Rise above" relates to the idea that creative knowledge building entails working toward more inclusive principles and higher---level formulations of problems. "Constructive Uses of Authoritative Sources" relates to the idea that knowing the authoritative sources that mark the current state of knowledge and its frontiers is a key to knowing a discipline. Knowledge innovation requires respect and understanding of these sources, combined with a critical stance towards them. The "Concurrent, Embedded, and Transformative Assessment" principle relates to the idea that assessment is part of the effort to advance knowledge. The community engages in its own internal assessment, which is both more fine-tuned and rigorous than external assessment. 
It seems that the three models surveyed above are not adequate in the sense that they don't develop into instructional designs with procedural frameworks that can be implemented in learning settings. The Ways of Knowing model (Belenky et al, 1998) is an epistemic one, focusing on the epistemological development of individuals. Although it highlights the nature of knowledge and ways of knowing learners are to adopt along the various stages of their epistemic development, it does not provide instructional advice on how to improve students' ways of knowing or knowledge management behaviors and processes. The Knowledge Chain Model (Singh, 2012) is basically developed within business fields and thus focuses on organizational knowledge management, a context that might be totally different in structure and purpose from educational settings. Nevertheless, it highlights the different processes, both primary and secondary, that are required to manage knowledge for better achievement of goals. Both models focus on existing knowledge and thus don't provide a step forward towards creating new knowledge or reformulating established knowledge in a creative way.

Bereiter and Scardmilia's model $(2014,2010,2002)$, on the other hand, focuses on knowledge building and advancement. Three characteristics are of value for educational practices and pedagogies. The first is that the model emphasizes idea advancement and building of new knowledge that is of value to the community, which in turn would help advance existing knowledge into new realms that might help learning communities achieve their goals in a better way. Second, the model focuses on the collective advancement of knowledge, an orientation that seems more commensurate with connectivist learning environments and the emerging forms of virtual communities including the community of practice, community of interest, and community of inquiry in addition to the community of learning (Chatti et al, 2010; So \& Brush, 2008; Liu et al, 2007; Shea, 2006; Palloff \& Pratt, 2005). Third, the model is developed within virtual learning settings and thus seems commensurate with the paradigm shift towards connectivist learning environments and pedagogies (Siemens, 2008). Yet, although the model provides insights into the processes and principles of building new knowledge, it lacks instructional advice regarding how these insights and principles would be translated into instructional frameworks adaptable to foreign language learning contexts in particular.

\subsection{A Suggested Model}

Fuelled by the inadequacies of the existing models of knowledge management discussed above, the current study proposes a knowledge-management model that integrates the three models into a comprehensive instructional framework to help prospective EFL teachers manage their pedagogical knowledge for better foreign language instruction. The suggested model begins with reframing epistemological stances of learners, i. e. their beliefs about the nature of knowledge, where it resides, and how it should be acquired and evaluated (Schoommer-Aikins \& Easter, 2009, Hofer, 2008). This phase is a prerequisite to any effective knowledge management or knowledge building. It targets reframing students' epistemological beliefs towards pedagogical knowledge so that they see knowledge as incremental, developmental, and acquired through effort and perseverance from a multiplicity of sources rather than transmitted from authoritative sources, be it the teacher or the assigned textbooks.

The second phase focuses on establishing a knowledge management and knowledge building community in a connectivist environment. Principles of Bereiter and Scardamalia's (2010) knowledge building in terms of (1) community knowledge, (2) democratizing knowledge, (3) symmetric knowledge building, and (4) knowledge building discourse, as discussed in the above sections, work best in this phase. Here students are guided into establishing cognitive and social norms for participation in knowledge building by different community members. Establishing these cognitive and social norms, as So et al (2012), Zhang et al (2007) and Stahl (2006) argue, constitute a determinant factor in the success of knowledge building and knowledge management endeavors.

The third phase encompasses the core processes of knowledge management as discussed in the Knowledge Chain Model (Singh, 2012) as well as those proposed in the pertinent literature on knowledge management (Hiew \& Hoon, 2014; Ma \& Yuen, 2011; King, 2009; Friesen, 2008). These include knowledge discovery and detection, knowledge acquisition, knowledge organization and assessment, knowledge refinement, knowledge transfer, knowledge sharing, knowledge reuse, and knowledge creation. These in turn are classified into two sub-categories. The first focuses on basic knowledge management strategies targeting acquisition, coordination, and assessment of established knowledge. The second focuses on higher-level strategies dealing with building and creation of new knowledge. The first category of strategies constitutes a prerequisite for the second category as one has to digest existing knowledge and judge its value in terms of usefulness, applicability, and credibility before moving on to generating new knowledge. This suggested model was field-tested on a cohort of prospective EFL teachers' in the Emirati context to investigate its impact on developing their ideational flexibility and engagement in virtual foreign language learning settings.

\section{Method}

\subsection{Participants}

Eighteen prospective EFL teachers participated in this study. They were enrolled in the final year of their English study program and were doing their practicum experience at Abu Dhabi and Alain schools, both public and private. As ADU is a multinational university, participants came from different countries including, Emirates, Syria, Egypt, the Sudan, Palestine, Lebanon, India, Iran, Pakistan, Somalia, and Oman. They were all female as the English program in ADU admits female students only. 


\subsection{Design of the Study}

The study utilized the one-group quasi-experimental design with pre-post assessment procedures. Students were preassessed for their ideational flexibility and engagement in foreign learning settings. An instructional intervention based on the suggested knowledge management instructional framework was then introduced to enhance their knowledge management strategies in virtual learning environment. The Discussion Board of the Blackboard learning platform adopted by ADU was used as a workspace to establish the knowledge management community of prospective EFL teachers. By the conclusion of the instructional intervention, they were post-assessed for their ideational flexibility and engagement in virtual language learning settings.

\subsection{Instructional treatment}

The instructional treatment aimed at enhancing the knowledge management strategies of prospective EFL teachers in virtual learning environments. It focused on the pedagogical knowledge deemed important for language teachers to effectively handle language learning contexts and manage professional knowledge in an effective way. The instructional treatment focused on core knowledge management strategies deemed significant in pertinent literature (Hiew \& Hoon, 2014; Ma \& Yuen, 2011; King, 2009; Friesen, 2008). These included knowledge discovery and collection, knowledge acquisition, knowledge organization and assessment (analysis \& synthesis), knowledge refinement, knowledge transfer, knowledge sharing, knowledge application and reuse, and knowledge creation.

The instructional procedures followed the framework of knowledge management suggested by the end of the literature review. It proceeded through three different phases. The first phase focused on reframing prospective EFL teachers' epistemic stances about pedagogical knowledge so that they be oriented towards adaptive epistemological frameworks regarding knowledge. These adaptive frameworks, as epistemic theorists (Schommer-Aikins \& Easter, 2009; BaxterMagolda, 2004) state, are anchored by beliefs in knowledge as incremental rather than fixed, drawn from a multiplicity of sources rather than limited to the one source of knowledge represented by instructors or assigned textbooks, and can be advanced through constructivist pedagogies and proper cognitive processing faculties.

The second phase focused on establishing an online community using the Discussion Board. Principles of online communities in terms of social and cognitive presence were stressed and a code of conduct established so that participants came to common understanding regarding expectations and requirements. Technical issues regarding how to use the Discussion Board, how to create discussion threads, how to upload files to the Blackboard, and how to scaffold, support, and improvise on own and others' work were all handled.

The third phase of the treatment focused on developing the knowledge management strategies as outlined above. Emphasis was given to two broad areas including creative adaptation of established pedagogical knowledge and creating new knowledge through knowledge building procedures. In particular, the following detailed instructional framework was followed:

1. The procedures often started with teacher presentations regarding assigned readings and topics of language teaching in the TEFL-II course. The theoretical background about the topics of discussion and some applications in foreign language settings were detailed. Then, an open discussion with the students followed to activate their background knowledge and identify their entry knowledge base regarding the topics of discussion.

2. Then, students were asked to survey different knowledge sources of pertinent literature on the topic of discussion. Consistent with Evens et al. (2015) regarding sources of pedagogical knowledge, students were asked to consult multiple resources including actual teaching experience, professional content knowledge courses (TEFL courses in this case), disciplinary knowledge (knowledge about the language system), observation, cooperation with colleagues, and reflection.

3. To develop understanding of and respect for the authoritative sources of knowledge in the sense explained by Bereiter and Scardamalia (2010) in their knowledge building model, students were asked to consult different sources of knowledge, contrast ideas and viewpoints, and come up with a synthetic summary of the collected information.

4. Synthetic summaries were then posted on the Discussion Board under appropriate threads for discussion and feedback by peers and the instructor.

5. Collective responsibility for knowledge building and improvisation was stressed by encouraging individual contributions to the discussions going therein.

6. Students were encouraged to use scaffold supports such as "My Perspective" "I'd Suggest" "I'd Add That", and "New Information" so that they develop their own viewpoints and take the discussion ahead towards creative adaptation or improvisation on discussed ideas.

7. Knowledge building and idea advancement techniques were established through using "Rise Above" entries where prospective teachers can add any further developed ideas or suggested instructional practices.

8. The next phase, students were asked to write a digest on discussed ideas, techniques, and knowledge on threaded topics, embodying their own perspectives and the new ideas they developed on the topic of discussion.

9. Individual digests were then uploaded to the Blackboard for a further cycle of feedback and improvisation by peers and the instructor. 
10. The procedure was repeated with other topics and areas of pedagogical knowledge explored in threaded discussions. Yet, discussions were progressively oriented towards more knowledge building and better knowledge management. The treatment lasted for three months.

\subsection{Instrumentation \& Scoring Procedures}

Two dependent variables were considered in the current study, including the ideational flexibility of prospective EFL teachers and their engagement in virtual language activities. To assess the impact of enhancing knowledge management strategies on the prospective EFL teachers' ideational flexibility, the researcher used two types of tasks including a contextualized task and a decontextualized one. Their engagement in virtual language activities was assessed via an engagement scale.

\subsubsection{Ideational Flexibility}

Since ideational flexibility is the ability to generate a heterogeneous pool of responses or to use a variety of categories and themes when producing ideas, alternative uses tasks (AUT), as recommended by Lubart et al. (2013), were used for tapping this ideational flexibility. In alternative uses tasks (AUT), respondents are required to name as many different ways a given item might be used. This was applied to the contextualized task as well as the decontextualized one. In the contextualized task students were asked to write reflective reports on "Ways of motivating students in foreign language classes". These reflective reports represent integrated reading-writing tasks where students could survey existing literature on the topic, synthesize existing information, and add their own perspectives to creatively adapt existing knowledge to the current context of foreign language instruction.

The decontextualized task was a kind of brainstorming task where students were asked to brainstorm individually on "Ways of using educational movies in their EFL classes". This was a timed task where students had to brainstorm individually on the assigned topic for fifteen minutes. Here, they were asked to create a list of suggestions rather than write reports as was the case in the contextualized task.

Students' responses on both tasks were evaluated by two raters (inter-rater reliability $=.89$ ). They were trained beforehand in how to identify themes and decide on their variability in the AUT tasks. Each different alternative / theme was given a mark. Scores given by the two raters were then averaged to obtain a prospective EFL teacher's total score on ideational flexibility in the contextualized task and the decontextualized one. The total ideational flexibility score for an individual prospective teacher was the sum of averaged scores they got on both tasks.

\subsubsection{Student Engagement Scale}

The prospective EFL teachers' engagement in virtual language learning environments was tapped via an engagement scale developed from the Deep Learning Items of the National Survey of Student Engagement (cited in Kuh, 2009; Pascarella et al, 2009). Fifteen items dealing with deep learning approaches of university students were revalidated on 245 students in the Emirati context of Higher Education. A confirmatory factor analysis procedure with Varimox rotation was conducted on students' responses to the scale items. Eigen Value of $\geq 1$ and a minimum item loading of .05 were used as bases for the factor analysis procedure. Items that loaded on more than one factor or those with item loadings less than 0.5 were excluded. Three of the fifteen items had loadings less than 0.5 and were thus excluded from the scale.

Examination of the resulting scree plot suggested a three-factor solution similar to that of the National Survey of Student Engagement (cited in Pascarella et al, 2009). The first of these factors is higher order learning (4 items), referring to leaning experiences requiring higher order cognitive processes such as application, analysis, judgment, and synthesis. The second is integrative learning (5 items), referring to ability to connect concepts, perspectives, readings, and learning experiences when handling novel and complex issues and challenges. The third factor is reflective learning (6 items), referring to learners' ability to assess their own weaknesses and strengths and monitor their learning performance for better achievement of goals.

The scale is a Likert-type Scale with 5-point scoring scheme anchored with "Strongly Agree" to "Strongly Disagree" to items of the questionnaire. Items included both negative and positive statements. Those with negative statement were reverse coded in the scoring procedure so that higher scores on the scale indicated higher levels of student engagement in foreign language learning; the opposite holds true for lower scores.

\section{Results of the Study}

By the conclusion of the instructional treatment, prospective EFL teachers' scores on the ideational flexibility tasks and the Student Engagement Scale were calculated, tabulated and compared to their pre-assessment scores. The Statistical Package for the Social Sciences (SPSS, V.22) was used in the statistical treatment of the results. as shown below.

\subsection{Impact on Ideational Flexibility}

The prospective EFL teachers' scores on the pre-post assessment of their performance on the alternative uses tasks (AUT) were calculated and tabulated for investigating the impact of the instructional intervention on their ideational flexibility. Due to the small number of participants in the study, a non-parametric test was employed in the statistical treatment of the results. The Wilcoxon Singed-Ranks test was run on the pre-post assessment scores for any statistically significant difference in ideational flexibility between the pre-assessment and post-assessment results. Details are shown in Table (1). 
Table 1. Wilcoxon Signed-Ranks test of prospective EFL teachers' ideational flexibility

\begin{tabular}{|c|c|c|c|c|c|c|c|c|c|}
\hline & $\mathrm{N}$ & $\mathrm{M}$ & SD & $\begin{array}{c}\text { Positive } \\
\text { Ranks }\end{array}$ & Ties & $\begin{array}{l}\text { Mean } \\
\text { Rank }\end{array}$ & $\begin{array}{c}\text { Sum } \\
\text { of } \\
\text { Ranks }\end{array}$ & $\mathrm{Z}$ & $\begin{array}{c}\text { Asympt. } \\
\text { Sig. (2- } \\
\text { tailed) }\end{array}$ \\
\hline Flexibility_Scores_post & 18 & 11.47 & 1.74 & 16 & 2 & 8.5 & 136 & 3.54 & 000 \\
\hline Flexibility Scores Pre & 18 & 7.69 & .97 & & & & & & \\
\hline
\end{tabular}

As reflected by data in Table (1), the output of the Wilcoxon Signed-Ranks test shows a statistically significant difference between ranks of the prospective EFL teachers in the pre-post assessments of their ideational flexibility. The post-assessment ranks were statistically significantly higher than the pre-assessment ranks $(Z=3.54, P \leq 01)$. This, in turn, indicates that the prospective EFL teachers' ideational flexibility improved significantly as a result of enhancing their knowledge management strategies. Post instructionally, they showed more skillfulness in generating a rich pool of diverse ideas on the alternative uses tasks (AUT) utilized for assessing their ideational flexibility.

Based on their performance on the two ideational flexibility tasks, they did quite well in both the contextualized and the decontextualized contexts. The decontextualized task focused on their ability to generate a heterogeneous pool of ideas of value in the context of foreign language instruction. Their generated ideas increased in number and covered a wider range of alternatives and options suggested for using educational movies in foreign language settings.

The contextualized task focused on their ability to reflect on existing pedagogical knowledge and how they can creatively adapt it to language learning settings, on the one hand, and add their own perspectives and alternative techniques, on the other hand. After Lubart, et al (2013), assessment of students' creative potential in their reflective reports focused on two creative processes: divergent-exploratory and convergent-integrative. The divergent exploratory mode of thinking refers to the process of expanding the range of solutions in creative problem solving. The convergentintegrative mode of thinking refers to the process of combining, integrating, or synthesizing existing elements in new ways, and encompasses some convergent operations such as synthesis and evaluation.

Based on the quality of their reflective reports in terms of the number of formulated alternatives, it seems that the prospective EFL teachers showed more skillfulness in both types of thinking post-instructionally. They analyzed existing literature with a critical eye in terms of value and applicability of the available pedagogical knowledge in the Emirati foreign language context. As well, they used the existing pedagogical knowledge as a springboard towards formulating more creative ideas and alternative pedagogical practices.

\subsection{Impact on Student Engagement}

To decide on the impact of enhancing prospective EFL teachers' knowledge management strategies in virtual learning environments on their engagement in foreign language learning activities, their scores on the pre-post responses to the Student Engagement Scale were tabulated and analyzed. As the data was skewed for the considered variable, a nonparametric test was employed in the statistical treatment of the results. The Wilcoxon Singed-Ranks test was run on the pre-post assessment scores for any significant difference in the prospective EFL teachers' engagement in virtual language learning environments. Details are shown in Table (2).

Table 2. Wilcoxon Signed-Ranks test of prospective EFL teachers' engagement in the virtual learning environment

\begin{tabular}{|c|c|c|c|c|c|c|c|c|c|}
\hline & $\mathrm{N}$ & $\mathrm{M}$ & SD & $\begin{array}{l}\text { Negative } \\
\text { ranks }\end{array}$ & $\begin{array}{l}\text { Positive } \\
\text { ranks }\end{array}$ & $\begin{array}{l}\text { Mean } \\
\text { Rank }\end{array}$ & $\begin{array}{l}\text { Sum of } \\
\text { Ranks }\end{array}$ & $\mathrm{Z}$ & $\begin{array}{c}\text { Asympt. } \\
\text { Sig. (2-tailed) }\end{array}$ \\
\hline $\begin{array}{l}\text { Engagement_ } \\
\text { Score_post }\end{array}$ & 18 & 3.50 & .496 & 0 & 18 & 9.5 & 171 & 3.72 & 000 \\
\hline $\begin{array}{l}\text { Engagement_ } \\
\text { Score_Pre }\end{array}$ & 18 & 2.41 & .415 & & & & & & \\
\hline
\end{tabular}

As indicated by data in Table (2) there is a statistically significant difference between ranks obtained by the prospective EFL teachers in the pre-post assessment of their engagement in foreign language learning settings. The post-assessment ranks are statistically significantly higher than the pre-assessment ones $(Z=3.72, P \leq 01)$. This in turn indicates that the prospective EFL teachers' engagement in virtual language learning settings improved significantly as a result of enhancing their knowledge management strategies.

Based on their responses to the items of the Student Engagement Scale, they showed higher gains on the three different types of engagement included therein: higher order learning, integrative learning, and reflective learning. Their responses to the higher order learning items indicate that they developed more acumen to analyze ideas and theories and examine situations and language teaching conditions in more depth. They became more able to synthesize and organize 
information, ideas, and experiences into new more complex interpretations and relationships. They became more experienced in judging information, data, methods, and pedagogical knowledge in terms applicability and value when applied to foreign language learning contexts.

In terms of integrative learning, they became more able to integrate ideas and information from different sources of pedagogical knowledge and embrace a diversity of perspectives in discussions and writing assignments. As well, they put together ideas and concepts from different TEFL and language courses. Most importantly, they showed more tendency to integrate their own ideas, readings, and experiences with those of peers and the instructor, which in turn gave them chances to develop more comprehensive understandings of foreign language teaching and learning issues and practices.

Their responses to the reflective learning items of the Student Engagement Scale showed more tendency to reflect on their language learning experiences and the pedagogical knowledge pertinent to foreign language teaching and learning in their context. They examined the strengths and weaknesses of own and others' views regarding foreign language instruction practices and showed more tendency to connect with others and see viewpoints and issues from their vantage point. They showed more skillfulness in handling questions and issues that have no clear answers or clear conclusions and in applying course learnings to their own language teaching issues and problems. Most importantly, they enjoyed completing challenging tasks requiring investment in time and mental effort.

\section{Discussion}

The results of the study reported above show that enhancing knowledge management strategies of prospective EFL teachers brought about significant gains in their creativity in foreign language teaching/learning settings as measured in terms of their ideational flexibility. As well, their engagement in foreign language learning activities and processes in terms of higher-order learning, integrative learning, and reflective learning has improved significantly. These results are consistent with conclusions of previous studies regarding the impact of knowledge building and knowledge management on teaching and learning (Keong \& Subhi, 2015; Hiew \& Hoon, 2014; Usman \& Oyefolahan, 2014; Zaqout \& Abbas, 2012; Cheng et al, 2011; Hou, 2011; Richardson \& Ice, 2010; Chen et al, 2009; Pelletier et al, 2006).

This significant impact of knowledge management on student performance can be interpreted in terms of a number of features that knowledge management in virtual learning environments availed in a way that was unlikely to exist in traditional learning settings. The first of these features is the induction of a learning atmosphere conducive to enhancing knowledge building culture amongst students. Here, students are more oriented towards knowledge building rather than adopting knowledge that might be outdated or unsuitable in terms of its value and applicability in their context of foreign language instruction. This seems to have changed their perceptions about learning from transmissive to constructivist orientations. Instead of taking for granted the pedagogical knowledge in their assigned readings, they indulged in a process of evaluating knowledge, integrating it with knowledge gained from other sources, and adapting both based on the requirements of their current context of foreign language instruction. This way, they took the established knowledge as a springboard towards knowledge advancement. Bereiter and Scardamalia (2014, 2010, 2002) consider this knowledge building culture a cornerstone in knowledge advancement.

Establishing this knowledge building culture is a prerequisite condition for reframing students' epistemic positions. Epistemic positions here refer to beliefs that students hold regarding the nature of knowledge, how it is constructed and evaluated, and how knowing occurs (Hofer, 2008; Schommer-Aikins, 2008). When students believe that knowledge is absolute and fixed, they take for granted whatever omniscient figures such as teachers and the more knowledgeable others say or do. Thus doing, they focus on memorizing knowledge and emulating authorities in deeds and words. Contrariwise, when students believe that knowledge is constructed rather than transmitted, ideas can be critiqued, worked upon, refined, refuted, or further developed based on credibility and value. Both knowledge building advocates (Scardamalia et al, 2012; Zhang et al, 2011; Bereiter \& Scardamalia, 2010) and epistemic researchers (SchommerAikins, 2008; Hofer, 2008; Baxter-Magolda, 2004) see sophisticated epistemology as a determinant factor in constructing and advancing knowledge.

Another feature that knowledge management in virtual learning environments availed is the collective advancement of knowledge. Two keywords are stressed here: advancement and collective. The former relates to the point discussed in the previous section regarding the knowledge building culture, where students are oriented towards knowledge building and advancement rather than knowledge transmission. The latter relates to the collaborative work towards this knowledge building and advancement. In Discussion Boards, the prospective EFL teachers put ideas together, built on one another's ideas, and consequently took ideas to new horizons in a way that was unlikely in individualistic environments.

This seems consistent with conclusions in pertinent literature regarding the value of collaborative cognition in knowledge building and management. According to Bereiter and Scardamalia (2010), knowledge building is best practiced in a community. This community is characterized by two significant features. On the one hand, students are proactive and independent learners in the collaborative sense (Chan \& Chan 2011). This is crucial for avoiding the dependency and passivity that may characterize more instructor-focused forums (King, 2009). On the other hand, idea diversity is a main principle of knowledge building and advancement (Bereiter \& Scardamalia, 2010). Here knowledge is advanced in a symmetric way as expertise is distributed between and among participants. They gain knowledge through participation in a joint effort. This collaboration is particularly important in language settings (Hiew \& Hoon, 2014; Skinner, 2009; Kuh et al, 2008; Zhao \& Kuh, 2004). 
A third feature that might have contributed to the effectiveness of the knowledge management strategies is that knowledge management has both feedback and feedforward effects. Feedback is represented in the kind of constructive advice that students exchanged on their work while discussing issues, negotiating ideas together, and exchanging viewpoints regarding discussed topics. Mutual assessment of ideas, contributions, and suggestions gave students a chance to look at their ideas from different perspectives and thus had a more comprehensive view of how others see their work. Salter and Conneely (2015), and Gikandi et al (2011) see that formative feedback and authentic assessment are excellent ways to encourage quality participation and interaction and thus facilitate knowledge building and sharing.

The feedforward effect of knowledge management, on the other hand, is represented in the generative value of knowledge building. According to Bereiter and Scardamalia (2010), "the value of knowledge in knowledge building pedagogy is to build more knowledge" (P.8). The more students acquire and build knowledge the more they feel that they are still in need of more knowledge and the cycle goes on and expands in terms of the quantity and quality of generated ideas. It seems that the Discussion Board was a viable tool for students to build on each other's ideas and to provide the social support needed for engagement in idea analysis and advancement. Stated in Scardamalia and Bereiter's words "advances within the communal spaces continually generate further advances with problems reformulated at more complex levels that bring a wider range of knowledge into consideration"(P.8).

A fourth significant feature of the knowledge management pedagogy is the cognitive engagement of students. As explained in the review of literature section, cognitive engagement constitutes an intricate problem in virtual learning environments (Zhang et al, 2007; Vaughan \& Garnison, 2005). Students are often engaged socially and emotionally but not cognitively. They might spend hours surfing the internet with little educational value in terms of academic achievement or intellectual work. Wise et al (2011) argue that social networks alone might not be adequate for securing student engagement unless coupled with rich activities and cognitively challenging tasks. It seems that knowledge management pedagogy was more effective than existing approaches in inducing higher levels of cognitive engagement on the part of prospective EFL teachers. This cognitive engagement has been shown in literature to bring about better language performance and learning gains (Shea, 2006; Arnold \& Ducate, 2005; Pawan et al, 2003; Rovai, 2002), higher order critical thinking (Richardson \& Ice, 2010), and better contributions in discussions (Cheng et al, 2011; Hou, 2011).

The scaffolding provided by students to peers in the Discussion Board environment might have been a determinant factor, too. Scaffolding here refers to "providing assistance and guidance to enable learners to accomplish tasks and develop understandings that they would not be able to manage on their own" (Hammond \& Gibbons, 2005:8). One of the basic principles of knowledge management pedagogy is the collaborative advancement of knowledge. Students mutually support each other, build on one another's ideas, and provide scaffolds so that ideas and perspectives are taken into new horizons that are not within the reach of individual endeavors. According to Tarchi (2013), high-level knowledge work is further supported through the use of scaffolds. Miyazoe and Anderson (2010) argue that constructivism and knowledge building, involving reflective and collaborative learning, and supported by scaffolding, are crucial for a quality online learning environment. Empirical research conclusions linked collaboration and scaffolding to creativity and innovation (Paulus \& Nijistad, 2003), motivation to move beyond the cognitive-situative divide and combine individual and social processes (Jarvela et al., 2010), significant growth in productive written vocabulary (Sun et al, 2008), and higher levels of engagement (Zhao \& Kuh, 2004; Skinner, 2009).

A final factor that might have contributed to the effectiveness of the current instructional intervention relates to the nature and provisions of the Discussion Board as a virtual learning environment. Virtual learning environments are characterized by a number of features that are not available in traditional environments (Hiew \& Hoon, 2014; Ma \& Yuen, 2011; Zhang \& Sun, 2011; Skinner, 2009; Chen et al, 2009; Siemens, 2008). The first of these is the abundance of knowledge resources made available to students at a press of a button. Knowledge can be easily contrasted, hyperlinked, mashed-up, and integrated in ways that are unlikely in traditional learning environments. Second, contrary to traditional learning environments characterized by sequential and hierarchical communication patterns, virtual learning environments allow for simultaneous participation by all learners. As the communication hierarchy principle is not applicable here, both good and poor learners can contribute positively without dominance by the bright ones. Finally, students have chances to work at their own convenience and at their own pace. Here, the learning environment is extended to outside of the traditional classroom walls and adapted to individual student needs, capabilities, and availability. Foreign language research literature indicates that these features made a difference in student learning in terms of motivation and satisfaction (Jarvelaa et al, 2010), interaction and contribution to the discussions (Lee, 2004), critical thinking and group creativity (Paulus \& Nijstad, 2003; Abrams, 2005) and the overall language performance (Belz \& Kinginger, 2002).

\section{Implications}

Although the current study is mainly concerned with knowledge management strategies of tertiary EFL students, implications might extend to other stages and contexts of foreign language instruction. Below is a set of implications for foreign language teachers, educational policy makers and decision takers, as well as future research on knowledge management.

\subsection{Implications for language Teachers}

Based on the instructional intervention suggested herein and the positive impact it had on students' creativity in terms of their ideational flexibility as well as their engagement in foreign language learning settings, a pressing need arises to revisit the instructional practices of language teachers for more orientation towards knowledge management and 
knowledge building pedagogies. The structural approaches and rote learning practices dominating foreign language classrooms provide little opportunity for developing creativity and productivity. These need reframing in terms of the kind of knowledge accented therein and processing mechanisms thereof. Fixed content and ended tasks need to be replaced by open-ended and incremental knowledge tasks. Tasks focusing on reproducing knowledge transmitted by others need to be replaced by tasks requiring constructing one's knowledge, understandings, and creative contributions to knowledge building and advancement. As well, multiplicity of knowledge sources, diversity of viewpoints and perspectives, and divergence rather than conformity need to be emphasized so that students move from tunneled visions to ones reflecting diversity and tolerance of differing points of view. These all should be core components of teacher education programs; otherwise, the cycle of dysfunctional instructional practices will reinforce itself and carry over to future students.

An area related to the previous one is the structure of the foreign language learning environments. The traditional buildings-and-books environments of education in general and foreign language education in particular would not do much to enhance knowledge productivity amongst learners. Dependence on assigned textbook readings and teachers as the only sources of knowledge is likely to result in learners being knowledge recipients rather than constructors. Knowledge is fragmented, distorted, and delivered in a way that yields no real value for application and very small window for creativity, improvisation, and development. These learning environments need restructuring in a way that, as Bedford (2013) recommends, would help learners do knowledge management. Consistent with Bereiter and Scardamalia's (2010) recommendation, "the flow of information in the learning environment needs to be changed so that the teacher is no longer a limited bandwidth bottleneck through which most information passes"(P.6).

Of course, the two areas discussed above cannot be easily restructured without reframing foreign language teachers' and learners' beliefs about knowledge -- their personal epistemologies. Research on epistemological beliefs indicates that sophisticated epistemological beliefs are related to deeper cognitive processing and more constructivist practices (Ali \& Ammar, 2006; Baxter-Magolda, 2004). Knowledge building advocates, on the other hand, see that nurturing these sophisticated epistemologies is a prerequisite step towards successful knowledge building pedagogy. According to Sterelny (2005) and Bereiter and Scardamalia (2014), for example, a core component of knowledge building is the creation of epistemic artifacts, tools that service in the further advancement of knowledge. Whereas, as Scardamalia and Bereiter (2003) argue, in traditional learning environments students tend to say that the more they learn and understand the less there remains to be learned and understood, students in knowledge building classrooms tend to see searching and knowledge building as occurring in circles, each leading to a wider circle of knowledge building and advancement. The core epistemic belief here is that knowledge is not fixed or absolute and thus knowledge building and advancement should never come to an end (Jarvis, 2012). Thus, reframing teachers' and learners' maladaptive epistemological beliefs about knowledge should receive due attention in teacher education programs.

\subsection{Implications for Education Policymakers \& Curriculum Designers}

Another area that might be informed by the results of the current study relates to the educational policies and curriculum design. The prevailing top-down approaches to policy making and curriculum design are very unlikely to bring about valuable gains in knowledge building and management in educational settings. As described by Johnson (2009), in the almost universal top-down approaches, top-level education hierarchies determine the knowledge and skills to be acquired, the content to be covered, and assessment routines to be followed. Here, the criteria of excellence and quality education are focused on how far teachers and learners alike conform to preset standards and expectations. In most cases, this leaves very little window for improvisation, creativity, and knowledge advancement. Should knowledge building and advancement be the core competencies of education, then educational policies, goals, and curricular decisions need to be revisited in a way that allows for striking a balance between top-down and bottom-up approaches so that teachers and learners be cognizant of the rationale of the goals and the way they can contribute to or refine them.

An issue related to the above point is the need for educational services providers, both public and private, to avail technology infrastructure that would help enhance knowledge management, knowledge creation, and collaborative practice. Knowledge management and knowledge building depend to a great extent on the provision of edge technologies and state-of-the-art facilities. These would help learners aggregate content knowledge, develop own knowledge and perspectives, share and interact with others in knowledge building communities, and build a community of inquirers. Two examples of such technological infrastructure with real knowledge building capabilities are the Knowledge Forum described by Scardamalia and her colleagues (Scardmalia \& Bereiter, 2007; 2006; Zhang et al, 2009)) in the University of Toronto (Canada) and the GroupScribbles User Interface described by Chen and colleagues (2009) in the Singaporean National Institute of Education. Without such edge technological infrastructure, knowledge management and knowledge building pedagogies would not

\subsection{Implications for Further Research}

The current study focused on knowledge management and building strategies that, as Bereiter and colleagues (Bereiter \& Scardamalia, 2014, Zhang et al., 2011; Bereiter \& Scardamalia, 2010) argue, would be the future alternative of existing educational approaches and practices. Based on the results of the study reported herewith, enhancing knowledge management of the prospective EFL teachers brought about better gains in their ideational flexibility and engagement in foreign language learning settings. They showed more ability to suggest a wide variety of alternative instructional practices and to adapt pedagogical knowledge to their context of foreign language teaching. This seems encouraging to replicate the instructional intervention and study its impact on other language skills and variables such 
as writing and reading performance, communicative competence and oral language practice, argumentation and debating skills...etc.

Yet, as this pedagogy is relatively new in educational settings, a lot of issues are still pending for investigation and future research before generalizing conclusions. One such an issue is the transfer of knowledge building and knowledge management mechanisms across disciplines. Research on knowledge epistemologies and ontologies showed differences between hard domains of knowledge such as math, science, and the natural science and soft domains such as languages and the social sciences (Bromme et al., 2008; Muis et al., 2006 ). These domain-specific differences, as Muis et al (2006) argue, affect pedagogical knowledge and thus curricular choices and instructional decisions within these domains. Future research needs to study knowledge management and knowledge building mechanisms within respective disciplines to see if these are trans-disciplinary. The same applies to different cultural contexts and different language communities to see if knowledge management mechanisms would differ due to language status (L1 vs. L2 or FL) within the same community, on the one hand, and among different language communities (particularly EFL ones), on the other.

Moreover, a number of issues stem from the delimitations of the current study and need to be considered in future research before generalizing conclusions. The first of these is that the current study involved tertiary EFL students only. As Bereiter and colleagues (Bereiter \& Scardamalia, 2014, Zhang et al., 2011; Bereiter \& Scardamalia, 2010; Scardamalia \& Bereiter, 2006) argue, knowledge building processes are similar across different age levels. They argue that learners from early age are capable of doing knowledge management and building. This very strong assumption needs to be tested in terms of pre-tertiary students' capabilities to build knowledge and become "the frontiers of knowledge" in Scardamalia and Bereiter's words (2002: 1373). Immature epistemic stances especially in early ages, inadequate background knowledge -- both academic and professional, and lack of sufficient life and learning experiences might mitigate against knowledge building and advancement by younger language learners. Generalizing the current conclusions to early stages of foreign language education should be taken with care.

The second of these issues is that the prospective EFL teachers involved in the current study were all females as the English program in the ADU university admits female students only. Literature on gender differences in ways of knowing shows that gender shapes college students' approaches to the nature, limits, and certainty of knowledge (Schommer-Aikins, 2009, Baxter-Magolda, 2004). As well, language research literature indicates that gender differences do exist in language performance and proficiency of male and female students (Byram \& Hu, 2013; Nyikos, 2008). Further research is needed to see if gender differences in language performance and proficiency can be attributed to differences in their ways of knowing and knowledge management capabilities..

A final issue here is that the current study is concerned with pedagogical knowledge of pre-service teachers of English. As literature carries evidence that pedagogical knowledge can be impacted by teaching experience (Evens et al, 2015; Shanahan \& Tochelli, 2014)), generalizing results to in-service teachers should be taken with care. Replicating the study with in-service teachers to decide on the impact of teaching experience on knowledge management processes is necessary before generalizing conclusions.

\section{References}

Abrams, Z. (2005). Asynchronous CMC, collaboration and the development of critical thinking in a graduate seminar in applied linguistics. Canadian Journal of Learning Technology 31(2), 23-47.

Akbari, E., Naderi, A., Simon, R. \& Pilot, A. (2016). Student engagement and foreign language learning through online social networks. Asian-Pacific Journal of Second and Foreign Language Education, 1:4. DOI:10.1186/s40862-0160006-7.

Ali, M. F. \& Ammar, A. M. (2005). An investigation of the relationships between EFL pre-service teachers' epistemological beliefs and their learning strategies, teaching practices and foreign language classroom anxiety. Journal of Education \& Psychology (El-Minia College of Education), 15(1), 1-32.

Ammar, A. M. I \& Abdel-Majeed, U. (2006). Predicting gifted EFL students' goal orientation, cognitive engagement, perceived linguistic competence, and achievement with epistemological beliefs. Paper presented at the Regional Scientific Conference on Giftedness and Creativity, Jeddah, Saudi Arabia, August, 28-30.

Ammar, A. M. I (2010). EFL students' epistemic stances and their cognitive engagement in personal learning environments. Paper presented at the International Conference on Personal Learning Environments, Barcelona, Spain, July, 7-9.

Arnold, N. \& Ducate, L. (2006). Future foreign language teachers' social and cognitive collaboration in an online environment. Language Learning \& Technology 10(1): 42-66. Retrieved July, 14th , 2014, from http://lt.msu.edu/vol10num1/pdf/arnoldducate.pdf.

Attwell, G. (2007). Personal learning environment- the future of e-learning? E-learning Papers, 2 (1). ISSN 1887-1542. Retrieved on June 3rd, 2013 from www.elearningpapers.eu.

Balaji, M. S. \& Chakrabarti, D. (2010). Student interactions in online discussion forum: Empirical research from 'Media Richness Theory' perspective. Journal of Interactive Online Learning, 9(1), 1-22. Available at: http://www.ncolr.org/jiol/issues/pdf/9.1.1.pdf 
Ball, D. L., Thames, M. H. \& Phelps. G. (2008). Content knowledge for teaching: What makes it special?”Journal of Teacher Education, 59(5), 389-407.

Barbot, B., Besançon, M. \& Lubart, T. (2011). Assessing creativity in the classroom. The Open Education Journal 4 (1), $58-66$.

Barbot, B., Tan, M. Randi, J. Santa-Donato, G. \& Grigorenko, E. L. (2012). Essential skills for creative writing: Integrating multiple domain-specific perspectives. Thinking Skills and Creativity, 7(3), $209-223$. doi:10.1016/j.tsc.2012.04.006.

Baxter-Magolda, M. (2004). Evolution of a constructivist conceptualization of epistemological reflection. Education Psychologist, 39(1), 31-42.

Becerra-Fernandez, I. \& Gudi, A. (2008). An experiential approach to teaching knowledge management. International Journal of Teaching and Case Studies, 1(3), 171-188.

Bedford, D. (2013). A Case study in knowledge management education - Historical challenges and future opportunities. The Electronic Journal of Knowledge Management, 11(3), 199-213. Retrieved on May, 2014, from: www.ejkm.com.

Belenky, M. F., Clinchy, B. M., Goldberger, N. R. \& Tarule, J. M. (1997). Women's ways of knowing: The development of self, voice and mind. New York: Basic Books.

Belz, J. A., \& Kinginger, C. (2002). The cross-linguistic development of address form use in tele-collaborative language learning: Two case studies. The Canadian Modern Language Review, 59(2), 189-214.

Bennet, D. \& Bennet, A. (2008). The depth of knowledge: surface, shallow or deep?. VINE, 38 (4), 405 - 420.

Bereiter, C, \& Scardamalia M. (2014). Knowledge building and knowledge creation: One concept, two hills to climb. In S. C. Tan, H. J. So \& J. Yeo. Knowledge creation in education(PP.35-52). Singapore: Springer.

Bereiter, C., \& Scardamalia, M. (2002). Schooling and the growth of intentional cognition: Helping children take charge of their own minds. In B. Smith (Ed.), Liberal education in a knowledge society (pp. 245-277). Chicago: Open Court.

Bereiter, C., \& Scardamalia, M. (2010). Can children really create knowledge? Canadian Journal of Learning and Technology, 36(1). Retrieved on July 24, 2013 from http://www.ejlt.ca/indix.php/ejlt/articles/view/585.

Besançon, M., Lubart, T. I. \& Barbot, B. (2013). Creative giftedness and educational opportunities. Educational and Child Psychology, 30 (2), 79-88.

Brick, B (2011a). How effective are web 2.0 language learning sites in facilitating language learning? Compass: The Journal of Learning and Teaching at the University of Greenwich, 3, 57-63.

Brick, B (2011b). Social networking sites and language learning. International Journal of Virtual and Personal Learning Environments, 2(3), 18-31. Retrieved on June, 12, 2013, from www.igi-global.com.

Bromme, R., Kienhues, D., \& Stahl, E. (2008). Knowledge and epistemological beliefs: An intimate but complicate relationship. In M. S. Khine (Ed.), Knowing, knowledge, and beliefs: Epistemological studies across diverse cultures (PP.1-25). New York: Springer.

Byram, M. \& Hu, A. (2013). Routledge encyclopedia of language teaching and learning (2nd ed.). New York: Routledge.

Chan, C. K. K. \& Chan, Y. Y. (2011). Students' views of collaboration and online participation in Knowledge Forum. Computers \& Education, 57(1), 1445-1457. http://dx.doi.org/10.1016/j.compedu.2010.09.003

Chatti, M. A. Augustiawan, M. Jarke, M., \& Specht, M. (2010). Toward a personal learning environment framework. International Journal of Virtual and Personal Learning Environments, 1(4), 71-82.

Chen, P. S. D, Lambert, A. D. \& Guidry, K. R. (2010). Engaging online learners: The impact of web-based learning technology on college student . Computers \& Education, 54(5), 1222-1232.

Chen, W., Wen, Y. \& Looi, C. (2009). Knowledge building in second language learning. In S.C. Kong, et al (Eds.), Proceedings of the 17th International Conference on Computers in Education (pp. 336-340). Hong Kong: Asia-Pacific Society for Computers in Education.

Cheng, C. K., Paré, D. E., Collimore, L. M. \& Joordens, S. (2011). Assessing the effectiveness of a voluntary online discussion forum on improving students' course performance. Computers \& Education, 56(1), 253-261. http://dx.doi.org/10.1016/j.compedu.2010.07.024.

Chu, K. W., Wang, M., Zhou, S., \& Yuen, A. H. K. (2009). Teacher perception of knowledge management: A case study in a secondary school. Paper presented at the 4th International Conference on e-Learning, Toronto, Canada, 1617.

Coates, H. (2006) Student in campus-based and online education university connections. London: Routledge.

Cranfield, D. J. \& Taylor, J. (2008). Knowledge management and higher education: A UK case study. The Electronic Journal of Knowledge Management, 6(2), 85 - 100. Retrieved on June 14th , 2013 from www.ejkm.com.

Davies, D., Jindal-Snape, D. Collier, C., Digby, R. Hay, P. \& Howe, A. (2013). Creative learning environments in education: A systematic literature review. Thinking Skills and Creativity, 8, 80-91. 
Dinkleman, T., Margolis, J \& Sikkenga, K. (2006). From teacher to teacher educator: Experiences, expectations, and expatriation. Studying Teacher Education, 2(1), 5-25.

Dunne, E, Wren, J, \& Janes, A (2012). Using video and wiki technology to increase student engagement with learning in large international cohorts in UK. Higher Education, 6(Part A), 165-194.

Evens, M., Elen, J. \& Depaepe, F. (2015). Developing pedagogical content knowledge: Lessons learned from intervention studies. Education Research International (2015). Available online at: http://dx.doi.org/10.1155/2015/790417.

Friesen, S. (2008). Effective teaching practices - A framework. Toronto: Canadian Education Association.

Garrett, C. (2011). Defining, detecting, and promoting student in college learning environments. Teaching \& Learning Journal, 5(2), 1-12.

Ge, X., Zhang, X. M., \& Wang, Q. (2006). The development of teachers specialization in the perspective of educational knowledge management. Computer Knowledge and Technology, 13(12), 227-228.

Gee, J. P. \& Hayes, E. R. (2011). Language and learning in the digital age. London: Taylor \& Francis.

Gikandi, J. W., Morrow, D. \& Davis, N. E. (2011). Online formative assessment in higher education: A review of the literature. Computers \& Education, 57(4), 2333-2351. http://dx.doi.org/10.1016/j.compedu.2011.06.004.

Hammond, J. \& Gibbon, P. (2005). What is scaffolding? In A. Burns \& H. Joyce (Eds.), Teachers' voices 8: Explicitly supporting reading and writing in the classroom (pp. 8-16). Sydney: National Center for English Language Teaching and Research.

Hiew, Y., \& Hoon, T. B. (2014). Factors affecting knowledge sharing among ESL undergraduates in completing collaborative writing tasks using Wiki and Skype. The English Teacher, XLIII(2), 46-62.

Hofer, B. K. (2008). Personal epistemology and culture. In M. Khine (Ed.), Knowing, knowledge, and beliefs: Epistemological studies across diverse cultures (pp. 3-22). New York: Springer.

Hofer, B. K. (2008). Personal epistemology and culture. In M. S. Khine (Ed.), Knowing, knowledge and beliefs: Epistemological studies across cultures (pp. 3 - 22). Dorchert, the Netherlands: Kluwer Academic Publishers.

Hou, H. T. (2011). A case study of online instructional collaborative discussion activities for problem-solving using situated scenarios: An examination of content and behavior cluster analysis. Computers \& Education, 56(3), 712-719. http://dx.doi.org/10.1016/j.compedu.2010.10.013.

Jang, S.-J., Tsai, M.-F. \& Chen, H.-Y. (2013). Development of pedagogical content knowledge for novice and experienced university instructors: a case study. Teaching in Higher Education, 18(1), 27-39.

Jarvelaa, S., Volet, S. \& Jarvenoja, H. (2010) Research on motivation in collaborative learning: Moving beyond the cognitive-situative divide and combining individual and social processes. Educational Psychologist, 45(1), 15-27.

Jarvis, P. (2012). Towards a comprehensive theory of human learning. London: Routledge.

Johnson, P. (2009). The 21st century skills movement. Education Leadership, 67(1), 11-21.

Kahn, P. E. (2014). Theorising student in higher education. British Educational Research Journal, 40(6), $1005-1018$.

Kahu, E. R. (2013). Framing student in higher education. Studies in Higher Education, 38(5), 758-773.

Kaufman, J. C., \& Beghetto, R. A. (2009). Beyond big and little: The Four C Model of Creativity. Review of General Psychology 13 (1), 1-12. Http://doi:10.1037/a0013688.

Keong, Y. C. \& Subhi, S. N. (2015). The role of knowledge sharing in the learning process among Iraqi EFL postgraduate students in UKM. International Journal of Education and Research, 3(12), 185-198.

Khine, M. \& Hayes, B. (2010). Investigating women's ways of knowing: An exploratory study in the UAE. Issues in Educational Research, 20(2), 105-117.

Khine, M. (Ed.) (2008). Knowing, knowledge and beliefs: Epistemological studies across cultures. Dorchert(the Netherlands): Kluwer Academic Publishers.

King, W. R. (2009). Knowledge management and organizational learning. Annals of Information Systems 4, 3-13.

König , J. Lammerding, S., Nold, G., Rohde , A., Straub, S. \& Tachtsoglou, S. (2016). Teachers’ professional knowledge for teaching English as a foreign language: Assessing the outcomes of teacher education. Journal of Teacher Education, 67, 320-337.

Kop, R. (2011). The challenges to connectivist learning on open online networks: Learning experiences during a massive open online course, International Review of Research in Open and Distance Learning, 12(3), 19-38.

Kudryavtsev, V. T. (2011). The phenomenon of child creativity. International Journal of Early Years Education, 19(1), 45-53.

Kuh, G. D. (2009) The National Survey of Student Engagement : Conceptual and empirical foundations. New Directions for Institutional Research, 141, 5-20.

Kuh, G. D., Cruce, T. M., Shoup, R., Kinzie, J. \& Gonyea, R. M. (2008). Unmasking the effects of student on first-year college grades and persistence. The Journal of Higher Education, 79(5), 540-563. 
Kumaravadivelu, B. (2012). language teacher educator for a globalized society. New York: Routledge.

Lee, L. (2004). Native and nonnative speakers' perceptions of networked collaborative interaction: A socio-cultural approach. In L. Lomicka \& J. Cooke-Plagwitz (Eds.), Technology and the language teacher: The theoretical, historical, and practical interface (pp. 248-261). Boston: Heinle \& Heinle.

Levy, S. \& Campbell, H. (2007) Promoting motivation and among academically at-risk students. Widening Participation and Lifelong Learning, 9 (3), 17-25.

Liu, X., Magjuka, R., Bonk, C. \& Lee, S. (2007). Does sense of community matter? An examination of participants' perceptions of building leaning communities in online courses. Quarterly Review of Distance Education, 8(1), 9-24.

Lomicka, L, \& Lord, G (2009). Introduction to social networking, collaboration, and Web 2.0 tools. In L. Lomicka \& G. Lord (Eds.), The next generation: Social networks and online collaboration in foreign language learning. San Marcos: CALICO.

Lubart, T. I., Zenasni, F. \& Barbot, B. (2013). Creative potential and its measurement.” International Journal of Talent Development and Creativity 1 (2), 41-51.

Ma, W. \& Yuen, A. H. (2011). Understanding online knowledge sharing: An interpersonal relationship perspective. Computers \& Education, 56(1), 210-219. http://dx.doi.org/10.1016/j.compedu.2010.08.004.

Major, C. H. \& Palmer, B. (2006). Reshaping teaching and learning: The transformation of faculty pedagogical content knowledge. Higher Education, 51(4),619-647.

Mamta, B. \& Jayanthi R. (2012). Enhancing the teaching-learning process: a knowledge management approach. International Journal of Educational Management, 26(3), 313 - 329.

Margolin, H. (2014). Professional development of teacher educators through an transitional space: A surprising outcome of a teacher education program. Teacher Education Quarterly, 38(3), 7-25.

Mazzolini, M. \& Maddison, S. (2007). When to jump in: The role of the instructor in online discussion forums. Computers \& Education, 49(2), 193-213. http://dx.doi.org/10.1016/j.compedu.2005.06.011.

Miyazoe, T. \& Anderson, T. (2010). Learning outcomes and students' perceptions of online writing: Simultaneous implementation of a forum, blog, and wiki in an EFL blended learning setting. System, 38(2), 185-199. http://dx.doi.org/10.1016/j.system.2010.03.006.

Mohamed, M. S., O’Sullivan, K. J., \& Ribière, V. (2008). A paradigm shift in the Arab region knowledge evolution. Journal of Knowledge Management (12:5), 107-120.

Moradkhani, S., Akbari R., Samar, R. G. \& Kiany G. R. (2013). English language teacher educators’ pedagogical knowledge base: The macro and micro categories. Australian Journal of Teacher Education, 38(10), 123-141.

Mourgues, C. Barbot, B., Tan, M. \& Brigorenko, E. I. (2014). The interaction between culture and the development of creativity. In L. Arnett (Ed.), The Oxford handbook of human development and culture: An interdisciplinary perspective. Oxford: Oxford University Press.

Muis, K., Bendixen, L. \& Haerle, F. (2006). Domain-generality and domain-specificity in personal epistemology research: Philosophical and empirical reflections in the development of a theoretical framework. Educational Psychology Review, 18, 3-54.

Murray, J. \& Male, /t. (2005). Becoming a teacher educator: Evidence from the field. Teaching and Teacher Education, 21(2), 25-42.

National Research Council (2000). How people learn: Brain, mind, experience, and school. Washington, DC.: National Academy Press.

Nyikos, M. (2008). Gender and good language learners. In C. Griffis (Ed.), Lessons from good language learners (pp.73-82). Cambridge: Cambridge University Press.

O’Dell, C. \& Hubert, C. (2011). The new edge in Knowledge. New Jersey, Wiley.

Palloff, R. M. \& Pratt, K. (2005). Collaborating online: Learning together in community. San Francisco: Jossey-Bass.

Pascarella E.T., Seifert T.A. \& Blaich C. (2009). Validation of the NSSE Benchmarks and Deep Approaches to Learning against Liberal Arts Outcomes. University of Iowa Center for Research on Undergraduate Education, Iowa City.

Pascarella, E. T., Seifert, T. A. \& Blaich, C. (2010). How effective are the NSSE benchmarks in predicting important educational outcomes? Change: The Magazine of Higher Learning, 42(1), 16-22.

Paulus P. B., \& Nijstad B. A. (2003). Group creativity: Innovation through collaboration. New York: Oxford University Press.

Pawan, F., Paulus, T. M. Yalcin, S.\& C. (2003). Online learning: Patterns of and interaction among in-service teachers. Language Learning \& Technology 7(3), 119-140.

Pelletier, J., Reeve, R., \& Halewood, C. (2006). Young children's knowledge building and literacy development through knowledge forum. Early Education and Development, 17(3), 323-346. 
Perkel, D. (2008). Copy and paste literacy? Literacy practices in the production of a MySpace profile. In K. Drotner, H. S. Jensen, \& K. C. Schroeder (Eds). Informal learning and digital media: Constructions, contexts, and consequences (pp. 203-24). Newcastle, UK: Cambridge Scholars Publishing.

Ravindran, B. Greene, B. \& DeBacker, T. (2005), Predicting preservice teachers' cognitive engagement with goals and epistemological beliefs. The Journal of Educational Research, 98(4), 222-232.

Richardson, J. C. \& Ice, P. (2010). Investigating students' level of critical thinking across instructional strategies in online discussions. The Internet and Higher Education, 13(1-2), 52-59. http://dx.doi.org/10.1016/j.iheduc.2009.10.009.

Richardson, S. \& Coates, H. (2010) AUSSE Research Briefing. Camberwell, Australia: Australian Council for Educational Research.

Rovai, A. P. (2002). Sense of community, perceived cognitive learning, and persistence in asynchronous learning networks. The Internet and Higher Education 5(4): 319-332.

Runco, M. (2001). Flexibility and originality in children's divergent thinking. The Journal of Psychology, 120(4), 345352.

Ruth, S., Shaw, N. \& Frizzel, V. (2003). Knowledge management education: An overview of programs of instruction. In C. W. Holsapple (Ed.), Handbook of Knowledge Management 2 (pp.581-603). Berlin, Springer-Verlag.

Salter, N .P. \& Conneely, M. R. (2015). Structured and unstructured discussion forums as tools for student . Computers in Human Behavior, 46, 18-29.

Scardamalia M, Bereiter C. (2006). Knowledge building: Theory, pedagogy, and technology. In K Sawyer (Ed.), Cambridge handbook of the learning sciences(pp. 97-118). Cambridge: Cambridge University Press.

Scardamalia M, Bransford J, Kozma R, \& Quellmalz E. (2012). New assessments and environments for knowledge building. In P. Griffin, B. McGaw, \& E. Care (Eds.) Assessment and Teaching of 21st Century Skills (pp.231-300). New York: Springer Science + Business Media.

Scardamalia, M. (2003). Knowledge building environments: Extending the limits of the possible in education and knowledge work. In A. DiStefano, K. E. Rudestam, \& R. Silverman (Eds.), Encyclopedia of distributed learning (pp. 269-272). Thousand Oaks, CA: Sage Publications.

Scardamalia, M., \& Bereiter, C. (2006). Knowledge Building: Theory, pedagogy, and technology. In K. Sawyer (Ed.), Cambridge Handbook of the Learning Sciences (pp. 97-118). New York: Cambridge University Press.

Scardamalia, M., \& Bereiter, C. (2007). Fostering communities of learners and knowledge building: An interrupted dialogue. In J. C. Campione, K. E. Metz, \& A. S. Palincsar (Eds.), Children's learning in the laboratory and in the classroom: Essays in honor of Ann Brown (pp. 197-212). Mahwah, NJ: Erlbaum.

Scardmalia, M. \& Bereiter, C. (2002). Knowledge building. In J. W. Guthrie (Ed.), Encyclopedia of Education (2nd ed.) (pp. 1370-1373). New York: McMillan.

Schommer-Aikins, M. \& Easter, M. (2006). Ways of knowing and epistemological beliefs: combined effect on academic performance. Educational Psychology, 26(3), 411-423.

Schommer-Aikins, M. \& Easter, M. (2009). Ways of knowing and willingness to argue. The Journal of Psychology, 143(2), 117-132.

Shanahan, L. E. \& Tochelli, A. L. (2014). Examining the use of video study groups for developing literacy pedagogical content knowledge of critical elements of strategy instruction with elementary teachers. Literacy Research and Instruction, 53(1), 1-24.

Shea, P. (2006). A study of students' sense of learning community in online environments. Journal of Asynchronous Learning Networks, 10(1), 35-44. Retrieved on July 15, 2013 from http://www.sloan-c.org/publications/jaln/v10n1 /v10n1_4shea_member.asp.

Shreiner, L. A. \& Louis, M. C. (2011) The engaged learning index: Implications for faculty development. Journal on Excellence in College Teaching, 22(1), 5-28.

Siemens, G. (2008). New structures and spaces of learning: The systemic impact of connective knowledge, connectivism, and networked learning. Retrieved on May, 25, 2013 from http://elearnspace.org/articles/systemic_impact.htm.

Singh, M. (2012). A Framework for teaching knowledge management as a college course. International Journal of Humanities and Social Science, 2(6), 193-203.

Skinner, E. (2009) Using community development theory to improve student in online discussion: A case study. Journal of Research in Learning Technology, 17(2), 89-100.

So, H. J. \& Brush, T. A. (2008). Student perceptions of collaborative learning, social presence, and satisfaction in a blended learning environment: Relationships and critical factors. Computer \& Education, 51(1), 318-336.

So, H.-J., Seah, L.H., \& Toh-Heng, H.L. (2010). Designing collaborative knowledge building environments accessible to all learners: Impacts and design challenges. Computers \& Education, 54, 479-490.

Sousa, D.A. (2006), How the Brain Learns, Corwin Press, Thousand Oaks, CA. 
Stahl G. (2006). Group cognition: Computer support for building collaborative knowledge. MA: MIT Press.

Sterelny, K. (2005). Externalism, epistemic artifacts and the extended mind. In (R. Schantz, ed) The Externalist Challenge: New studies on cognition and intentionality. Berlin: De-Gruyter.

Sun, Y., Zhang, J. \& Scardamalia, M. (2008). Knowledge building and vocabulary growth over two years, Grades 3 and 4. Instructional Science, 38(2), 147-171. doi:10.1007/s11251-008-9082-5.

Swan, K. (2004). Learning online: Current research on issues of interface, teaching presence and learner characteristics. In J. Bourne \& J. C. Moore (Eds.), Elements of quality online education: Into the mainstream. (pp. 63-79). Needham, MA: Sloan Center for Online Education. http://sloanconsortium.org/node/925.

The United Nations Development Programme / Regional Bureau for Arab States (UNDP/RBAS) \& Mohamed Bin Rashid Foundation (2014). Arab Knowledge Report 2014: Youth and Localisation of Knowledge. Dubai: Alghurair Printing \& Publishing.

Tochan, F. (2010). Deep education. Journal of Educators, Teachers, and Trainers, 1, 1-12.

Usman, S. H., \& Oyefolahan, I. O. (2014). Encouraging knowledge sharing using Web 2.0 technologies in higher education: A survey. International Journal of Managing Information Technology (IJMIT), 6(2), 19-28.

Van-Driel J. H. \& Berry, A.(2012). Teacher professional development focusing on pedagogical content knowledge. Educational Researcher, 41(1), 26-28.

Vaughan, N. \& Garrison, D. R. (2005). Creating cognitive presence in a blended faculty development community. Internet and Higher Education 8, 1-12.

Warner, D. (2006). Schooling for the knowledge era. Camberwell: ACER Press.

Wright, K. (2005). Personal knowledge management: Supporting individual knowledge worker performance. Knowledge Management Research and Practice, 3(3), 156-165.

Zaqout, F., \& Abbas, M. (2012). Towards a model for understanding the influence of the factors that stimulate university students' and performance in knowledge sharing. Library Review, 61(5), 345-361.

Zhang, J., \& Sun, Y. (2011). Quantified measures of online discourse as knowledge building indicators. In H. Spada, S. G., N. Miyake, \& N. Law (Eds.), Connecting computer-supported collaborative learning to policy and practice: CSCL2011 conference proceedings (Vol. 1, pp. 72-79). Hong Kong, China: ISLS

Zhang, J., Hong, H.-Y., Scardamalia, M., Teo, C. L., \& Morley, E. A. (2011). Sustaining knowledge building as a principle-based innovation at an elementary school. Journal of the Learning Sciences, 20(2), 262-307. http://doi:10.1080/10508406.2011.528317 .

Zhang, J., Scardamalia, M., Lamon, M., Messina, R., \& Reeve, R. (2007). Socio-cognitive dynamics of knowledge building in the work of 9- and 10-years olds. Educational Technology, Research and Development, 55(2), $117-145$.

Zhang, J., Scardamalia, M., Reeve, R., \& Messina, R. (2009). Designs for collective cognitive responsibility in knowledge-building communities. The Journal of the Learning Sciences, 18, 7-44.

Zhao, C. and Kuh, G. D. (2004). Adding value: Learning communities and student . Research in Higher Education. 45(2), 115-138.

Zhao, J. (2010). School knowledge management framework and strategies: The new perspective on teacher professional development. Computers in Human Behavior, 26(2), 168-175.

Zydney, J. M., DeNoyelles, A. \& Kyeong-Ju, S. K. (2012). Creating a community of inquiry in online environments: An exploratory study on the effect of a protocol on interactions within asynchronous discussions. Computers \& Education, 58(1), 77-87. http://dx.doi.org/10.1016/j.compedu.2011.07.009. 